\title{
Mean Baseline Removal Method
}

National Cancer Institute

\section{Source}

National Cancer Institute. Mean Baseline Removal Method. NCI Thesaurus. Code

C64239.

Method for identifying invariant set normalization baseline using mean expression values.

Defined in the documents available at

http://bioconductor.org/packages/1.9/bioc/html/affy.html. 